Research article

\title{
Body composition of women and men with complete motor paraplegia
}

\author{
Lisa A. Beck ${ }^{1}$, Jeffry L. Lamb ${ }^{1}$, Elizabeth J. Atkinson ${ }^{2}$, Lisa-Ann Wuermser ${ }^{3}$, \\ Shreyasee Amin, 4,5
}

${ }^{1}$ Department of Physical Medicine and Rehabilitation, College of Medicine, Mayo Clinic, Rochester, MN, USA, ${ }^{2}$ Division of Biomedical Statistics and Informatics, Department of Health Sciences Research, College of Medicine, Mayo Clinic, Rochester, MN, USA, ${ }^{3}$ Department of Physical Medicine and Rehabilitation, Emory University School of Medicine, Atlanta, GA, USA, ${ }^{4}$ Division of Rheumatology, Department of Medicine, College of Medicine, Mayo Clinic, Rochester, MN, USA, ${ }^{5}$ Division of Epidemiology, Department of Health Sciences Research, College of Medicine, Mayo Clinic, Rochester, MN, USA

Objectives: To examine body composition, including the relationship between body mass index (BMI) and total body fat, in women and men with complete motor paraplegia and to make comparisons with able-bodied controls.

Methods: In 13 subjects with traumatic, complete motor paraplegia (six women, seven men) and 39 sex-, age-, and BMI-matched controls from the community (18 women, 21 men), we measured total and regional (upper extremities, trunk, and lower extremities) lean and fat mass using total body dual-energy X-ray absorptiometry. Results: Both women and men with paraplegia had significantly lower lean mass in their lower extremities, as would be expected, and in their total body when compared with controls. However, they had significantly greater lean mass in their upper extremities than controls $(4.4 \mathrm{~kg}$ vs. $3.6 \mathrm{~kg}, \mathrm{P}=0.004$ and $8.6 \mathrm{~kg}$ vs. $6.7 \mathrm{~kg}$, $\mathrm{P}<0.001$ in women and men, respectively); all subjects with paraplegia studied used manual wheelchairs. Although total body fat mass was significantly greater in women $(P=0.010)$ and men $(P=<0.001)$ with paraplegia compared with controls, for the equivalent total body fat mass, BMI was actually lower in women and men with paraplegia than controls (e.g. $20.2 \mathrm{~kg} / \mathrm{m}^{2}$ vs. $25.0 \mathrm{~kg} / \mathrm{m}^{2}$, respectively).

Conclusion: We report on body composition in persons with complete motor paraplegia, including women on whom limited information is currently available. Our results support the need to define better assessments of obesity in both women and men following spinal cord injury, particularly of central body fat distribution, as BMI underestimates adiposity in this population.

Keywords: Body composition, Body mass index (BMI), Fat tissue mass, Lean tissue mass, Paraplegia, Percent body fat, Spinal cord injury

\section{Introduction}

In the last decade, heart disease has become one of the leading causes of death following chronic spinal cord injury (SCI) for both women and men. ${ }^{1-4}$ As a result, evaluation and mitigation of cardiovascular risk factors has taken on increasing importance in the clinical care of persons with chronic SCI, in whom a key reversible risk factor is obesity. ${ }^{5}$ The assessment of obesity is difficult in the SCI population, as traditional clinical measures, such as body mass index (BMI), may underestimate adiposity, ${ }^{6,7}$ likely, in part, related

Correspondence to: Lisa A. Beck, Department of Physical Medicine and Rehabilitation, College of Medicine, Mayo Clinic, 200 First Street SW, Rochester, MN 55905, USA. Email: beck.lisa@mayo.edu to the loss of lean muscle mass. ${ }^{8}$ There is growing awareness and interest in the importance of understanding body composition following chronic SCI, as that would assist development of appropriate clinical assessment tools and targets regarding body fat for this population.

Persons with chronic SCI are reported to have an increase in percent fat mass and reduced lean tissue, ${ }^{7,9-11}$ which is felt to be due to their relative physical inactivity. ${ }^{12}$ While BMI is widely used as a marker of obesity, ${ }^{13}$ which is a predictor of cardiovascular disease, ${ }^{14}$ men with SCI are reported to have up to $13 \%$ greater fat mass compared to able-bodied men with the same BMI. ${ }^{15}$ However, studies examining 
body composition following SCI have often combined subjects with both tetraplegia and paraplegia, which may not be ideal as the relative activity level is different between both groups, and even among those with different degrees of paraplegia. There are even some data to suggest a greater prevalence of obesity in paraplegia than in tetraplegia. ${ }^{16,17}$ Furthermore, despite the proportion of women with SCI having increased over the last 25 years (http://www.NSCISC.UAB.edu), most studies examining body composition have involved men and, to the best of our knowledge, there has been only one report ${ }^{18}$ describing body composition for women with SCI specifically. In contrast to persons with tetraplegia, women and men with paraplegia physically have a greater ability to reverse inactivity and thereby potentially reduce obesity as a cardiovascular risk factor. ${ }^{19}$

Therefore, the goals of our study were to examine body composition, including the relationship between BMI and total body fat, in both women and men with chronic complete motor paraplegia, and to make comparisons with sex-, age-, and BMI-matched ablebodied controls from the general community population.

\section{Methods}

Study participants

\section{Spinal cord injury subjects}

Women and men between the ages of 20 and 50 years with traumatic, complete motor paraplegia (American Spinal Injury Association Impairment Scale (AIS) A or B) ${ }^{20}$ for at least 2 years were recruited from the clinical practice of an academic SCI center and through an additional database of people with SCI. All subjects used manual wheelchairs. Study participants (six women and seven men; all white, non-Hispanic) had a level of injury between T3 and T12 and their time since injury ranged from 2 to 26 years.

\section{Population-based control subjects}

Comparisons were made to an established populationbased cohort, representing an age-stratified, random sample of Rochester, Minnesota, residents ${ }^{21}$ who had similar measurements made of their body composition as those made of the study subjects with SCI. The cohort spanned ages from 21 to 97 years and included 375 women and 325 men, $98 \%$ of whom were white, reflecting the ethnic composition of the community. This population is highly characteristic of the U.S. white population. ${ }^{22}$ Subjects between the ages of 20 and 50 years were then matched, in a 3:1 ratio, to SCI subjects by sex, age \pm 5 years, and BMI $\pm 5 \mathrm{mg} / \mathrm{kg}^{2}$.
None of the subjects with SCI or matched controls had severe renal insufficiency (glomerular filtration rate $($ GFR $)<30 \mathrm{ml} /$ minute $\left./ 1.73 \mathrm{~m}^{2}\right)^{23}$ or were current oral corticosteroids users. Prior to matching, we also excluded any control subjects who had an underlying neuromuscular disease (e.g. stroke, multiple sclerosis, and myasthenia gravis).

The study was approved by the Institutional Review Board and all subjects provided written informed consent.

\section{Body composition measurements}

Body composition was assessed using the Lunar Prodigy instrument (Lunar Prodigy, Madison, WI, USA). Total body lean mass $(\mathrm{kg})$ and total body fat mass $(\mathrm{kg})$ was determined from the whole body scan (coefficient of variation (CV), 1.6 and 2.6\%, respectively). From these scans, separate assessments of the lean and fat mass of the upper extremities, trunk, and lower extremities could be determined (Fig. 1).

BMI $\left(\mathrm{kg} / \mathrm{m}^{2}\right)$ was calculated from the height and weight of each subject. Each SCI subject was weighed in their wheelchair, and then the wheelchair alone was weighed, with the difference being the body mass $(\mathrm{kg})$ of the subject. Self-reported height prior to their injury was recorded for subjects with paraplegia. Each control subject's weight was measured in light clothes

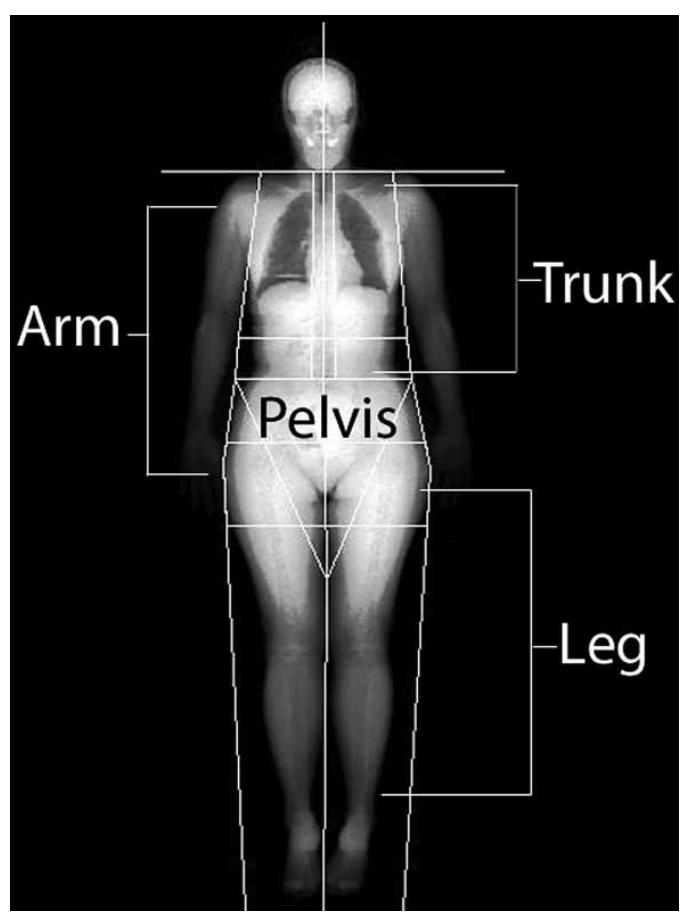

Figure 1 GE Lunar Prodigy total body scan for estimates of total body and regional lean and fat mass. The area in the triangle (pelvis) is not included in the trunk or lower extremity estimates. 
without shoes and their height was measured using a stadiometer.

\section{Statistical analyses}

Analyses were performed separately for women and men. We used linear regression analyses to test for differences in body composition variables between the subjects with SCI and controls, after adjusting for age and BMI. Linear regression analyses were also used to examine the relationship between BMI and percent fat in both groups. Analyses were performed using SAS 9.3 and R 2.14 and the significance level was set at 0.05 .

\section{Results}

We studied six women and seven men with traumatic, complete motor paraplegia, all of whom were white, non-Hispanic. Individual characteristics related to their history of SCI are presented in Table 1. Among the six women with paraplegia, three women had high thoracic spinal cord lesions, occurring between T3 and $\mathrm{T} 7$, while three had lesions between $\mathrm{T} 9$ and $\mathrm{T} 12$. There were two women who had spastic lower extremities, while the remaining four were flaccid. Among the seven men with paraplegia, there were three who had high thoracic spinal cord lesions occurring between T3 and $\mathrm{T} 7$, while four men had lesions between $\mathrm{T} 9$ and T12. Spasticity was noted in five men, while the other two men had flaccid lower extremities. Median duration of injury for women was 7 years (range 2-23 years), with two women living with SCI greater than 10 years. Men had a median duration of injury of 7 years (range 3-27 years), with three men living with SCI greater than 10 years.

We studied 39 matched control subjects (18 women and 21 men) who were also all white, non-Hispanic. The SCI and control subjects had similar age, height, weight, and BMI (Table 2).

\section{Total body and regional lean mass}

Total body lean mass was significantly lower in both women (adjusted mean difference $(95 \%$ confidence interval, CI): $-3.4 \mathrm{~kg}(-6.7,-0.2 \mathrm{~kg}))$ and men $(-7.1 \mathrm{~kg}(-11.5,-2.7 \mathrm{~kg}))$ with paraplegia from traumatic SCI when compared with their respective matched controls (Table 3). Women with paraplegia had significantly lower lean mass in the lower extremities $(P<0.001)$ but significantly greater lean mass in their upper extremities $(\mathrm{P}=0.004)$ than controls (Table 3). There were no differences in trunk lean mass between groups (Table 3). Similar to women,

Table 1 Characteristics related to their spinal cord injury in the 13 study subjects (six women and seven men)

\begin{tabular}{|c|c|c|c|c|c|}
\hline Subjects & Age (years) & Level of injury & AIS $^{*}$ & Spastic/flaccid & Duration of injury (years) \\
\hline \multicolumn{6}{|l|}{ Females } \\
\hline 1 & 34 & T3 & $A$ & Spastic & 17 \\
\hline 2 & 41 & T11 & $A$ & Flaccid & 2 \\
\hline 3 & 42 & T6 & $A$ & Flaccid & 9 \\
\hline 4 & 43 & $\mathrm{~T} 12$ & $A$ & Spastic & 23 \\
\hline 5 & 44 & $\mathrm{~T} 7$ & $A$ & Flaccid & 3 \\
\hline 6 & 44 & $\mathrm{~T} 12$ & $\mathrm{~B}$ & Flaccid & 6 \\
\hline \multicolumn{6}{|l|}{ Males } \\
\hline 1 & 25 & T5 & $A$ & Spastic & 7 \\
\hline 2 & 28 & $\mathrm{~T} 11$ & $A$ & Flaccid & 7 \\
\hline 3 & 45 & T9 & A & Flaccid & 6 \\
\hline 4 & 46 & T6 & A & Spastic & 27 \\
\hline 5 & 48 & T11 & B & Spastic & 3 \\
\hline 6 & 49 & T11 & A & Spastic & 27 \\
\hline 7 & 50 & T5 & A & Spastic & 15 \\
\hline
\end{tabular}

*American Spinal Injury Association Impairment Scale (AIS). ${ }^{20}$

Table 2 Clinical characteristics of 13 subjects with spinal cord injury and 39 able-bodied sex-, age-, and body mass index-matched control subjects

\begin{tabular}{|c|c|c|c|c|c|c|}
\hline \multirow[b]{2}{*}{ Characteristics } & \multicolumn{3}{|c|}{ Women } & \multicolumn{3}{|c|}{ Men } \\
\hline & $\mathrm{SCl}(N=6)$ & Able-bodied $(N=18)$ & P-value & $\mathrm{SCl}(N=7)$ & Able-bodied $(N=21)$ & P-value \\
\hline Age, years & $41.5 \pm 3.8$ & $41.2 \pm 3.9$ & 0.853 & $41.6 \pm 10.4$ & $41.4 \pm 8.5$ & 0.965 \\
\hline $\mathrm{BMI}, \mathrm{kg} / \mathrm{m}^{2}$ & $22.6 \pm 4.2$ & $23.0 \pm 3.3$ & 0.817 & $23.5 \pm 3.7$ & $24.8 \pm 2.8$ & 0.355 \\
\hline Height, cm & $170.1 \pm 7.8$ & $165.5 \pm 6.2$ & 0.156 & $184.0 \pm 8.0$ & $179.2 \pm 5.3$ & 0.079 \\
\hline Weight, kg & $65.3 \pm 13.2$ & $62.9 \pm 10.2$ & 0.656 & $79.1 \pm 8.4$ & $79.5 \pm 9.3$ & 0.916 \\
\hline$\%$ Total body fat & $45.5 \pm 10.2$ & $38.3 \pm 6.7$ & 0.002 & $35.9 \pm 12.0$ & $27.4 \pm 7.7$ & $<0.001$ \\
\hline
\end{tabular}


Table 3 Site-specific lean and fat mass of 13 subjects with spinal cord injury and 39 able-bodied sex-, age-, and body mass index-matched control subjects, by sex

\begin{tabular}{|c|c|c|c|c|c|c|}
\hline \multirow[b]{2}{*}{ Characteristics } & \multicolumn{3}{|c|}{ Women } & \multicolumn{3}{|c|}{ Men } \\
\hline & $\mathrm{SCl}(N=6)$ & Able-bodied $(N=18)$ & $P$ value* & $\mathrm{SCl}(N=7)$ & Able-bodied $(N=21)$ & P value* \\
\hline \multicolumn{7}{|l|}{ Lean mass } \\
\hline Total body, kg & $32.0 \pm 4.1$ & $35.6 \pm 3.2$ & 0.040 & $46.5 \pm 6.1$ & $53.8 \pm 4.3$ & 0.003 \\
\hline Trunk, kg & $16.6 \pm 1.9$ & $17.8 \pm 1.5$ & 0.168 & $22.4 \pm 3.7$ & $25.4 \pm 2.3$ & 0.018 \\
\hline Upper extremities, kg & $4.4 \pm 0.7$ & $3.6 \pm 0.6$ & 0.004 & $8.6 \pm 1.0$ & $6.7 \pm 0.6$ & $<0.001$ \\
\hline Lower extremities, kg & $8.3 \pm 1.8$ & $11.3 \pm 1.3$ & $<0.001$ & $11.5 \pm 2.6$ & $17.9 \pm 1.8$ & $<0.001$ \\
\hline \multicolumn{7}{|l|}{$\%$ Lean mass } \\
\hline Total body & $50.6 \pm 9.9$ & $57.8 \pm 6.5$ & 0.002 & $59.9 \pm 12.1$ & $68.5 \pm 7.4$ & $<0.001$ \\
\hline Trunk & $53.0 \pm 10.3$ & $59.2 \pm 8.2$ & 0.008 & $56.5 \pm 15.4$ & $65.4 \pm 9.0$ & 0.002 \\
\hline Upper extremities & $61.9 \pm 13.2$ & $59.5 \pm 6.0$ & 0.457 & $75.1 \pm 8.1$ & $75.0 \pm 6.4$ & 0.339 \\
\hline Lower extremities & $40.4 \pm 8.7$ & $53.2 \pm 6.3$ & $<0.001$ & $55.4 \pm 10.6$ & $69.7 \pm 6.9$ & $<0.001$ \\
\hline \multicolumn{7}{|l|}{ Fat mass } \\
\hline Total body, kg & $31.1 \pm 14.6$ & $24.4 \pm 7.5$ & 0.010 & $28.9 \pm 11.8$ & $22.2 \pm 7.8$ & $<0.001$ \\
\hline Trunk, kg & $14.9 \pm 6.4$ & $12.1 \pm 4.3$ & 0.012 & $17.0 \pm 8.0$ & $12.9 \pm 4.8$ & 0.001 \\
\hline Upper extremities, kg & $2.7 \pm 1.7$ & $2.2 \pm 0.8$ & 0.138 & $2.5 \pm 1.3$ & $1.9 \pm 0.8$ & 0.002 \\
\hline Lower extremities, kg & $12.6 \pm 6.4$ & $9.4 \pm 2.8$ & 0.018 & $8.4 \pm 2.5$ & $6.7 \pm 2.3$ & $<0.001$ \\
\hline \multicolumn{7}{|l|}{$\%$ Fat mass } \\
\hline Total body & $45.5 \pm 10.2$ & $38.3 \pm 6.7$ & 0.002 & $35.9 \pm 12.0$ & $27.4 \pm 7.7$ & $<0.001$ \\
\hline Trunk & $44.2 \pm 10.1$ & $38.3 \pm 8.3$ & 0.011 & $40.3 \pm 15.3$ & $32.1 \pm 9.2$ & 0.003 \\
\hline Upper extremities & $33.3 \pm 13.7$ & $35.5 \pm 6.4$ & 0.558 & $20.2 \pm 8.4$ & $19.8 \pm 6.7$ & 0.194 \\
\hline Lower extremities & $56.1 \pm 9.5$ & $42.6 \pm 6.5$ & $<0.001$ & $40.1 \pm 10.2$ & $25.4 \pm 7.2$ & $<0.001$ \\
\hline
\end{tabular}

${ }^{\star} \mathrm{P}$ values reflect models adjusted for age and BMI.

men with paraplegia had significantly lower lean mass at their lower extremities, and significantly greater upper extremity lean mass $(\mathrm{P}<0.001)$ when compared with controls (Table 3). In contrast to women, men with paraplegia had lower trunk lean mass than their controls (Table 3). Interestingly, the upper extremity percentage of lean mass was similar between both women and men with paraplegia and their matched controls, while the percentage of lean mass of the total body, trunk and lower extremity was lower in women as well as men with paraplegia when compared with their controls (Table 3).

\section{Total body and regional fat mass}

Total body fat mass was significantly greater in both women (adjusted mean difference $(95 \% \mathrm{CI}):+7.5 \mathrm{~kg}$ $(2.0,13.0 \mathrm{~kg}))$ and men $(+9.6 \mathrm{~kg}(5.2,14.0 \mathrm{~kg}))$ with paraplegia from traumatic SCI when compared with their respective matched controls (Table 3 ). When examining fat mass by body region, women with paraplegia had greater fat mass at all body regions studied relative to their controls, although it did not reach statistical significance at the upper extremities (Table 3). Trunk, upper extremity and lower extremity fat mass were all significantly greater in men with paraplegia than their matched controls (Table 3). When examining the proportion of fat mass by region, both women and men with paraplegia had significantly higher percent fat mass than controls in all regions except for the upper extremities, where it was similar between groups (Table 3).

\section{$B M I$ and percent total body fat mass}

Although study subjects were matched by BMI, women and men with paraplegia had significantly greater percent total body fat mass compared with their controls (adjusted mean difference $(95 \% \mathrm{CI}):+7.7 \%$ (3.2, $12.2 \%)$ and $(+11.1 \%(6.0,16.2 \%)$ for women and men, respectively) (Table 3). In both our female and male control subjects, a BMI of $25.0 \mathrm{~kg} / \mathrm{m}^{2}$ (upper limit of normal for BMI) predicted a proportion of total body fat that was equivalent to the proportion of total body fat that would be predicted for a BMI of $20.2 \mathrm{~kg} / \mathrm{m}^{2}$ in our women and men with paraplegia (Fig. 2). Overall women and men with paraplegia each had a $9.6 \%$ higher total body fat mass compared with controls for the same BMI.

\section{Discussion}

We report on body composition, including the relationship between BMI and total body fat, separately for women and men with complete motor paraplegia and compare them with able-bodied controls. Few studies are available on body composition of women with SCI and our findings add relevant information to this limited body of literature. Despite our relatively small sample size, we found that both women and men with paraplegia had greater lean mass in their upper extremities, when compared with controls, even though they had lower total body lean mass overall. We also observed that women and men with paraplegia had greater total body and regional fat mass when compared 

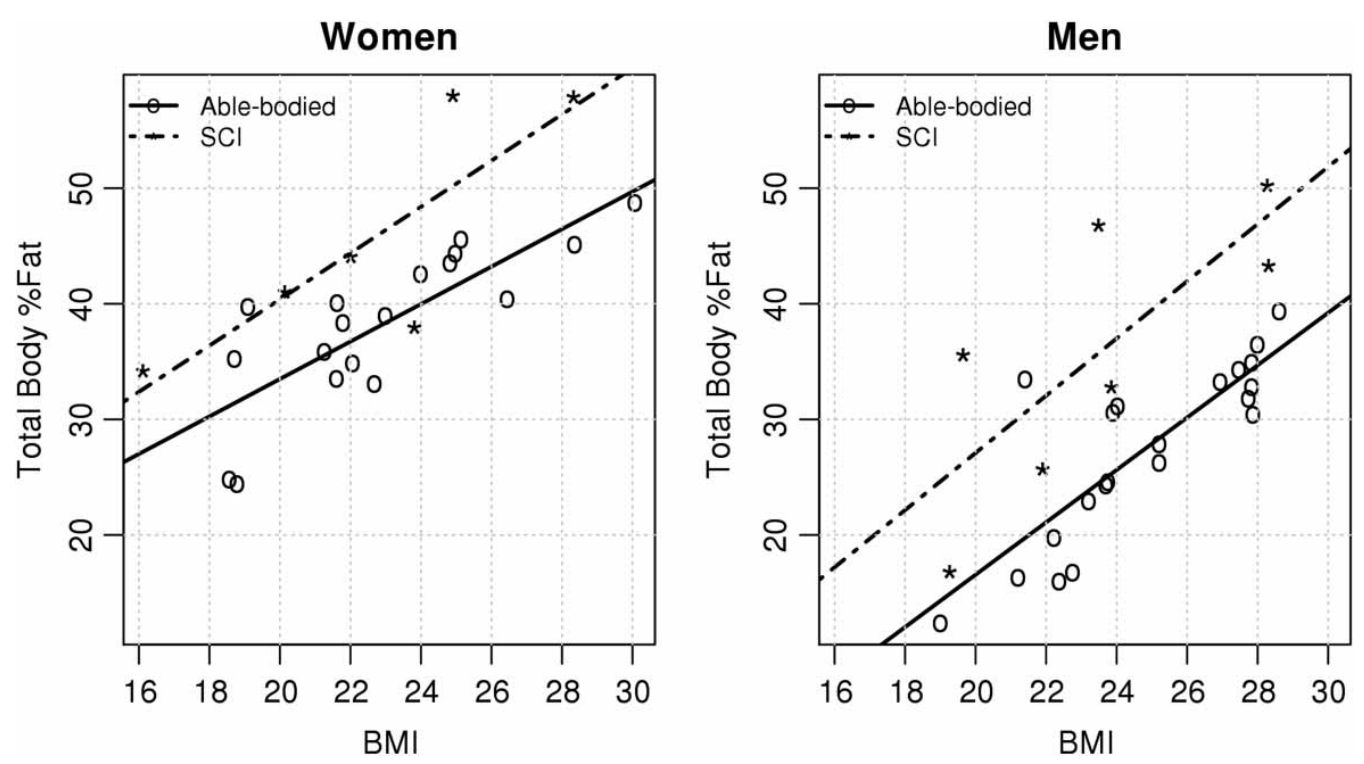

Figure 2 Scattered plots fitted with regression lines showing the relationship between percent total body fat and BMI $\left(\mathrm{kg} / \mathrm{m}^{2}\right)$ in men and women. For regression models involving subjects with complete motor paraplegia, the $R^{2}$ value was 0.68 for women and 0.58 for men. For regression models involving able-bodied controls, the $\boldsymbol{R}^{2}$-square value was 0.64 for women and 0.68 for men.

with controls. Nevertheless, for the equivalent total body fat mass, women as well as men with paraplegia had lower BMI values than controls, suggesting that BMI will underestimate obesity in both women and men with complete motor paraplegia.

Both women and men with SCI in our study had higher lean mass in their upper extremities when compared with their able-bodied controls. While this observation in a cohort of primary manual wheelchair users is not necessarily unexpected, this finding has not been previously reported in men. In contrast, Spungen et al. ${ }^{15}$ found men with paraplegia to have a significantly lower percentage of lean tissue in the upper extremities, but found no significant difference in absolute arm lean mass, when compared with able-bodied controls. While Maggioni et al. ${ }^{9}$ reported significantly higher fat free mass in the arms of persons with paraplegia than controls, fat-free mass accounts for both lean and bone tissue. In both studies, only male subjects with paraplegia were evaluated, and upper extremity use for transfers and wheelchair propulsion were not reported, irrespective of whether completeness of injury was documented. On the other hand, our findings of greater upper extremity lean mass in women with complete motor paraplegia than controls are consistent with results recently reported by Yarar-Fischer et al. ${ }^{18}$ in their population of women with paraplegia. Although we did not directly measure upper extremity activity in either our participants with SCI or their matched controls, our cohort with complete motor paraplegia all independently transferred themselves and propelled manual wheelchairs. It is possible that these activities contributed to their greater upper extremity lean mass relative to controls.

Persons with SCI are reported to acquire more fat mass over time, but also to lose lean mass due to disuse in areas of paralysis. ${ }^{10,24}$ We observed a greater proportion of fat mass particularly at the trunk and lower extremities of both women and men with paraplegia compared with controls. Our findings in men are consistent with reports by others studying men with complete motor paraplegia. ${ }^{9,10,15}$ In contrast to our results in women, the recent study by Yarar-Fischer et al. ${ }^{18}$ found no difference in the proportion of total or regional fat mass between women with paraplegia and controls. However, some of the women with paraplegia in their study had incomplete injuries and time since SCI was not reported. Whether that may have contributed to these differences with our findings is unclear. Interestingly, while we did observe a higher fat mass in the upper extremities of our subjects with paraplegia compared with controls, the percent fat mass was similar between the groups, both for women and men.

BMI is a tool to estimate excess body adiposity, and a BMI $>25 \mathrm{~kg} / \mathrm{m}^{2}$ is classified as overweight, while BMI $>30 \mathrm{~kg} / \mathrm{m}^{2}$ defines obesity. Although the corresponding percentage of body fat for a given BMI will vary by sex, age, and race/ethnicity, ${ }^{25}>25 \%$ body fat and $>35 \%$ body fat have been the suggested cutoffs for defining obesity in men and women, respectively, ${ }^{26}$ and generally are consistent with a BMI of $>30 \mathrm{~kg} / \mathrm{m}^{2} .{ }^{27}$ The participants with SCI in our study had BMI values that ranged 
from normal to overweight (non-obese), but the average percentage of total body fat was $>35 \%$ for men and $>45 \%$ for women. Thus, the majority of our participants fell into the obese range based on percentage of body fat even though their BMI did not indicate obesity. None of the participants appeared significantly overweight to the research team either. A growing number of studies have now shown that BMI underestimates obesity in persons with SCI. ${ }^{6,7,11,15,18,28,29}$ Spungen et al. ${ }^{15}$ reported that men with SCI have up to $13 \%$ more body fat than their able-bodied controls with the same BMI, results that are very similar to our findings of women and men with paraplegia both having almost $10 \%$ more body fat than their controls for any given BMI.

There have been ongoing efforts to determine a lower BMI cut off for persons with SCI. Indeed, Wahman et $a .^{29}$ and Laughton et al. ${ }^{6}$ proposed that a BMI > $22 \mathrm{~kg} / \mathrm{m}^{2}$ should be considered the cutoff for obesity in persons with SCI. However, increasingly it is being recognized in the general population that abdominal obesity is a better indicator of cardiovascular risk than BMI, and measures such as waist-to-hip ratio or waist circumference are being considered now as more appropriate tools in assessing obesity for risk stratification. ${ }^{30}$ Recently, Eriks-Hoogland et al. ${ }^{28}$ reported that waist circumference may be a potentially more promising measure of obesity than BMI in men with complete motor paraplegia. ${ }^{28}$ Our study demonstrated greater absolute and percent fat mass at the trunk for women as well as men with paraplegia compared with ablebodied controls, suggesting that waist circumference may also be useful in the assessment of obesity for women with SCI. Validation work would still be required. Nevertheless, it is unclear if the waist circumference values would be similar at predicting cardiovascular risk in SCI as in individuals without SCI. In addition, abdominal distension and loss of muscle tone still may confound measurements in most persons with SCI, except for the lowest levels of paraplegia, unless measured in recumbency. Regardless, rather than trying to identify different cutoffs of BMI to define obesity in women and men with SCI, efforts at better estimating central visceral adiposity to assess health risks may not only be more clinically relevant, but also more practical.

Based on our work and those of others, we conclude that obesity will be under-recognized in both women and men with paraplegia if traditional BMI cutoffs are used. As obesity is a potentially reversible risk factor for cardiovascular disease, early recognition is critical. Reversing obesity involves both diet and activity changes. While persons with paraplegia have enough intact upper body musculature to participate in aerobic activity, they still lack use of the larger muscles of their lower extremities, which limit calorie expenditure during exercise. Long-term interventions to reduce the relative decrease in lower extremity lean mass, such as with functional electrical stimulation (FES), are being studied. ${ }^{31-34}$ To date, only one study $^{34}$ has found a concomitant decrease in whole body fat, while the others have reported no change in adipose mass or body composition. FES may be a promising intervention to prevent muscle loss, and thereby reverse or prevent obesity, but the optimal frequency and duration of FES is still unknown. Regardless, a focus on healthy living and exercise need to be included in the rehabilitation program and lifelong care of both women and men with chronic complete motor paraplegia.

While we did not limit recruitment other than by age, our SCI population was entirely white, non-Hispanic, reflecting the local community population. However, we did study women as well as men with SCI. It is unclear if our observations can be extrapolated to other ethnicities and older age groups, including post-menopausal women. The number of participants with SCI in our study was small, but we were still able to observe significant differences in body composition at most sites relative to able-bodied controls. We also specifically chose to study persons with complete motor paraplegia. Body composition of persons with complete motor tetraplegia is likely to differ from our findings, given lack of volitional movement. In order to calculate BMI for persons with paraplegia, self-reported height was used with risk of potential errors in recall. However, given the age range of subjects studied, we would not have expected height loss. In exploratory analyses, neither level of injury, nor presence of spasticity, demonstrated any impact on lower extremity lean or fat mass; however, our subject number was too small to make a robust conclusion on these effects.

\section{Conclusion}

In summary, we found that upper extremity lean mass was greater in both women and men with complete motor paraplegia when compared with able-bodied controls. We hypothesize that these findings may be due to the fact that all our SCI participants independently transferred themselves and propelled manual wheelchairs. We also report that both women and men with complete motor paraplegia have greater overall and regional fat mass than able-bodied controls who were matched for BMI. Although our sample size was 
small, this study provides further needed evidence that BMI underestimates the percentage of total body fat in women, not just men, with complete motor paraplegia. Our findings support the need to identify better assessments of obesity in both women and men following SCI instead of relying on BMI. These study results would also endorse efforts at estimating central body fat distribution to define obesity in women and men with complete motor paraplegia.

\section{Acknowledgments}

This work was supported by a grant from the Craig H. Neilsen Foundation and made possible by research Grants AR027065, and UL1-RR024150 (Center for Translational Science Activities) from the National Institutes of Health, U.S. Public Health Service. The content is solely the responsibility of the authors and does not necessarily represent the official views of the National Institutes of Health.

\section{References}

1 Myers J, Lee M, Kiratli J. Cardiovascular disease in spinal cord injury: an overview of prevalence, risk, evaluation, and management. Am J Phys Med Rehabil 2007;86(2):142-52.

2 Garshick E, Kelley A, Cohen SA, Garrison A, Tun CG, Gagnon $\mathrm{D}$, et al. A prospective assessment of mortality in chronic spinal cord injury. Spinal Cord 2005;43(7):408-16.

3 Groah S, Weitzenkamp D, Sett P, Soni B, Savic G. The relationship between neurological level of injury and symptomatic cardiovascular disease risk in the aging spinal injured. Spinal Cord 2001;39(6): $310-7$.

4 Thietje R, Pouw MH, Schulz AP, Kienast B, Hirschfeld S. Mortality in patients with traumatic spinal cord injury: descriptive analysis of 62 deceased subjects. J Spinal Cord Med 2011;34(5): 482-7.

5 Lavis TD, Scelza WM, Bockenek WL. Cardiovascular health and fitness in persons with spinal cord injury. Phys Med Rehabil Clin N Am 2007;18(2):317-31, vii.

6 Laughton G, Buccholz A, Martin Ginis K, Goy R. Lowering body mass index cutoffs better indentifies obese persons with spinal cord injury. Spinal Cord 2009;47:757-62.

7 Jones L, Legge M, Goulding A. Healthy body mass index values often underestimate body fat in men with spinal cord injury. Arch Phys Med Rehabil 2003;84(7):1068-71.

8 Gater DR, Jr. Obesity after spinal cord injury. Phys Med Rehabil Clin N Am 2007;18(2):333-51, vii.

9 Maggioni M, Bertoli S, Margonato V, Merati G, Veicsteinas A, Testolin G. Body composition assessment in spinal cord injury subjects. Acta Diabetol 2003;40(Suppl 1):S183-6.

10 Spungen AM, Wang J, Pierson RN Jr, Bauman WA. Soft tissue body composition differences in monozygotic twins discordant for spinal cord injury. J Appl Physiol 2000;88(4):1310-5.

11 Buchholz AC, Bugaresti JM. A review of body mass index and waist circumference as markers of obesity and coronary heart disease risk in persons with chronic spinal cord injury. Spinal Cord 2005;43(9):513-8.

12 Demirel S, Demirel G, Tukek T, Erk O, Yilmaz H. Risk factors for coronary heart disease in patients with spinal cord injury in Turkey. Spinal Cord (Comparative Study) 2001;39(3):134-8.

13 Global database on body mass index World Health Organization (WHO). 2006. Available from: http://www.who.int/bmi/index. jsp?introPage=intro_3html.

14 Wilson WF, D'Agostino RB, Sullivan L, Parise H, Kannel WB. Overweight and obesity as determinant of cardiovascular risk the Framingham experience. Arch Inter Med 2002;162(16):1867-72.
15 Spungen A, Adkins R, Stewart C, Wang J, Pierson R Jr, Waters R, et al. Factors influencing body composition in person with spinal cord injury: a cross-sectional study. J Appl Physiol 2003;95(6): 2398-407.

16 Gupta N, White KT, Sandford PR. Body mass index in spinal cord injury - a retrospective study. Spinal Cord 2006;44(2):92-4.

17 Weaver FM, Collins EG, Kurichi J, Miskevics S, Smith B, Rajan S, et al. Prevalence of obesity and high blood pressure in veterans with spinal cord injuries and disorders: a retrospective review. Am J Phys Med Rehabil 2007;86(1):22-9.

18 Yarar-Fischer C, Chen Y, Jackson AB, Hunter GR. Body mass index underestimates adiposity in women with spinal cord injury. Obesity 2013;21(6):1223-5.

19 Van Loan MD, McCluer S, Loftin JM, Boileau RA. Comparison of physiological responses to maximal arm exercise among ablebodied, paraplegics and quadriplegics. Paraplegia 1987;25(5): 397-405.

20 Kirshblum SC, Burns SP, Biering-Sorensen F, Donovan W, Graves $\mathrm{DE}$, Jha $\mathrm{A}$, et al. International standards for neurological classification of spinal cord injury (revised 2011). J Spinal Cord Med 2011;34(6):535-46.

21 Riggs BL, Melton Iii LJ III, Robb RA, Camp JJ, Atkinson EJ, Peterson JM, et al. Population-based study of age and sex differences in bone volumetric density, size, geometry, and structure at different skeletal sites. J Bone Miner Res 2004;19(12):1945-54.

22 Melton LJ III. History of the Rochester Epidemiology Project. Mayo Clin Proc 1996;71(3):266-74.

$23 \mathrm{~K} / \mathrm{DOQI}$ clinical practice guidelines for chronic kidney disease: evaluation, classification, and stratification. Am J Kidney Dis 2002;39(2 Suppl 1):S1-266.

24 Wilmet E, Ismail AA, Heilporn A, Welraeds D, Bergmann P. Longitudinal study of the bone mineral content and of soft tissue composition after spinal cord section. Paraplegia 1995;33(11): 674-7.

25 Heo M, Faith MS, Pietrobelli A, Heymsfield SB. Percentage of body fat cutoffs by sex, age, and race-ethnicity in the US adult population from NHANES 1999-2004. Am J Clin Nutr 2012; 95(3):594-602.

26 AACE/ACE Obesity Task Force. AACE/ACE position statement on the prevention, diagnosis, and treatment of obesity. Endocr Pract 1998;4:297-350.

27 Gallagher D, Heymsfield SB, Heo M, Jebb SA, Murgatroyd PR, Sakamoto Y. Healthy percentage body fat ranges: an approach for developing guidelines based on body mass index. Am J Clin Nutr 2000;72(3):694-701.

28 Eriks-Hoogland E, Hilfiker R, Baumberger M, Balk S, Strucki G, Perret C. Clinical assessment of obesity in persons with spinal cord injury: validity of waist circumference, body mass index, and anthropometric index. J Spinal Cord Med 2011;34(4):416-22.

29 Wahman K, Nash MS, Lewis JE, Seiger A, Levi R. Cardiovascular disease risk and the need for prevention after paraplegia determined by conventional multifactorial risk models: the Stockholm spinal cord injury study. J Rehabil Med 2011;43(3):237-42.

30 Schneider HJ, Friedrich N, Klotsche J, Pieper L, Nauck M, John $\mathrm{U}$, et al. The predictive value of different measures of obesity for incident cardiovascular events and mortality. J Clin Endocrinol Metab 2010;95(4):1777-85.

31 Griffin L, Decker MJ, Hwang JY, Wang B, Kitchen K, Ding Z, et al. Functional electrical stimulation cycling improves body composition, metabolic and neural factors in persons with spinal cord injury. J Electromyogr Kinesiol 2009;19(4):614-22.

32 Skold C, Lonn L, Harms-Ringdahl K, Hultling C, Levi R, Nash $\mathrm{M}$, et al. Effects of functional electrical stimulation training for six months on body composition and spasticity in motor complete tetraplegic spinal cord-injured individuals. J Rehabil Med 2002; 34(1):25-32.

33 Scremin AM, Kurta L, Gentili A, Wiseman B, Perell K, Kunkel C, et al. Increasing muscle mass in spinal cord injured persons with a functional electrical stimulation exercise program. Arch Phys Med Rehabil 1999;80(12):1531-6.

34 Hjeltnes N, Aksnes A, Birkleland KI, Johansen J, Lannem A, Wallberg-Henrikssson H. Improved body composition after $8 \mathrm{wk}$ of electrically stimulated leg cycling in tetraplegic patients. Am Physiol Soc 1997;273(3 Pt 2):R1072-9. 